\title{
Inactivation Effect of Thymoquinone on Alicyclobacillus acidoterrestris Vegetative Cells, Spores, and Biofilms
}

\author{
Qiuxia Fan 1,2, Cheng Liu',2, Zhenpeng Gao 1,2, Zhongqiu Hu',2, Zhouli Wang ${ }^{1,2}$, \\ Jianbo Xiao ${ }^{4}$, Yahong Yuan ${ }^{1,2 *}$ and Tianli Yue ${ }^{1,2,3 *}$ \\ ${ }^{1}$ College of Food Science and Engineering, Northwest A\&F University, Yangling, China, ${ }^{2}$ Laboratory of Quality and Safety \\ Risk Assessment for Agro-Products (Yangling), Ministry of Agriculture, Yangling, China, ${ }^{3}$ College of Food Science \\ and Technology, Northwest University, Xi'an, China, ${ }^{4}$ Department of Analytical Chemistry and Food Science, Faculty of Food \\ Science and Technology, University of Vigo-Ourense Campus, Ourense, Spain
}

\section{OPEN ACCESS}

Edited by:

Lin Lin,

Jiangsu University, China

Reviewed by:

Antonio Bevilacqua,

University of Foggia, Italy

Veronica Ortiz Alvarenga,

Federal University of Minas Gerais,

Brazil

${ }^{*}$ Correspondence:

Yahong Yuan

yyh324@126.com

Tianli Yue

yuet/305@nwsuaf.edu.cn

Specialty section:

This article was submitted to

Food Microbiology,

a section of the journal

Frontiers in Microbiology

Received: 12 March 2021

Accepted: 21 April 2021

Published: 02 June 2021

Citation:

Fan Q, Liu C, Gao Z, Hu Z, Wang Z, Xiao J, Yuan $Y$ and Yue $T$

(2021) Inactivation Effect

of Thymoquinone on Alicyclobacillus acidoterrestris Vegetative Cells,

Spores, and Biofilms.

Front. Microbiol. 12:679808. doi: 10.3389/fmicb.2021.679808
Alicyclobacillus acidoterrestris (A. acidoterrestris), a spore-forming bacterium, has become a main challenge and concern for the juices and acid beverage industry across the world due to its thermo-acidophilic characteristic. Thymoquinone (TQ) is one of the active components derived from Nigella sativa seeds. The objective of this study was to investigate antibacterial activity and associated molecular mechanism of TQ against A. acidoterrestris vegetative cells, and to evaluate effects of $T Q$ on $A$. acidoterrestris spores and biofilms formed on polystyrene and stainless steel surfaces. Minimum inhibitory concentrations of TQ against five tested $A$. acidoterrestris strains ranged from 32 to $64 \mu \mathrm{g} / \mathrm{mL}$. TQ could destroy bacterial cell morphology and membrane integrity in a concentration-dependent manner. Field-emission scanning electron microscopy observation showed that TQ caused abnormal morphology of spores and thus exerted a killing effect on spores. Moreover, TQ was effective in inactivating and removing $A$. acidoterrestris mature biofilms. These findings indicated that $T Q$ is promising as a new alternative to control $A$. acidoterrestris and thereby reduce associated contamination and deterioration in the juice and acid beverage industry.

Keywords: spore-forming bacteria, Alicyclobacillus acidoterrestris, Nigella sativa, thymoquinone, inactivation effect, spores, biofilm

\section{INTRODUCTION}

A. acidoterrestris, a gram-positive, thermo-acidophilic, and spore-forming spoilage bacterium, is mainly responsible for the deterioration of acid products especially fruit juice, vegetable juice, and other relevant beverages (Keiichi and GOTO, 2006; Smit et al., 2011). This bacterium is extensively distributed in almost all components of the production and processing chain including the orchard, picking basket, fruit granary, fruit surface, cleaning water, pipeline water, production line, concentrated juice, semi-products, and final products (Chen et al., 2006; Driks et al., 2013; Huang et al., 2015). Compared to other food-associated bacteria, A. acidoterrestris has a greater tolerance to high temperatures and low $\mathrm{pH}$ environments. Moreover, under poor growth conditions, this microorganism can form endospores that are more resistant to thermo-acidic 
environments than vegetative cells and that could germinate, grow, and cause juice spoilage after reconstitution (Savaş Bahçeci et al., 2004). The characteristic of A. acidoterrestris grants it the ability to survive the commercial pasteurization process and also makes it a key quality control target for pasteurized fruit juices and relevant beverages. Juice deterioration by $A$. acidoterrestris resulted in the generation of guaiacol and halophenol compounds that were characterized by medicinal, smoky, and antiseptic tastes (Cai et al., 2015). The off-flavors of these compounds undermined the quality of the products (Pornpukdeewattana et al., 2020), which led to unaccepted products and substantial economic losses for the beverage industry.

Due to their distinctive structure, bacterial biofilms can form a barrier which will lessen and avoid the contact of bacterial cells in biofilms with disinfectants or antibacterial agents. Therefore, these biofilms cannot be inactivated or removed as easily as planktonic cells. Based on previous studies, A. acidoterrestris forms biofilms on different types of surfaces at food processing facilities including stainless steel, nylon, glass, and other surfaces (dos Anjos et al., 2013; Shemesh et al., 2014). It has been reported that $A$. acidoterrestris biofilm formation could be affected by many factors, such as strains, contact surface, and culture conditions (Basson et al., 2007; Prado et al., 2018). For the juice and beverage industry, the formation of A. acidoterrestris biofilms on the processing chain will lead to cross-contamination and thus increase the chance of product deterioration.

Currently, the food industry mainly relies on heat treatment, synthetic preservatives, and disinfectants to control contamination caused by $A$. acidoterrestris. Nevertheless, the former method affected the sensory quality of products, including color, flavor, and freshness, and ultimately caused reduced nutritional value. Meanwhile, the latter two methods (synthetic preservatives and disinfectants) may lead to adverse effects on human health. Consequently, there is a great need to search for safe, effective, and non-thermal methods to control A. acidoterrestris and its biofilms. As a nonthermal approach, natural compounds possessing antimicrobial activity has attracted more and more attention in recent years, especially phytochemicals.

Nigella sativa seeds (black seeds) have been used as a spice for thousands of years in the Middle East, India, and Pakistan. In Africa and Asia, these seeds were also used as a folk medicine to treat some diseases (Sutton et al., 2014). Thymoquinone (TQ, 2-methyl-5-isopropyl-1,4-benzoquinone), one of the functional constituents of the essential oil of Nigella sativa seeds, exhibits various pharmaceutical activities including anti-tumor, anti-inflammatory, anti-allergic, antidiabetic, antimicrobial, and hepatoprotective effects (Chehl et al., 2009; Aziz et al., 2011; Forouzanfar et al., 2014; Abdelrazek et al., 2018; Noorbakhsh et al., 2018; Yang et al., 2015). In addition, TQ was reported to be able to inhibit biofilm formation by some pathogenic bacteria including Cronobacter sakazakii (Shi et al., 2017), Pseudomonas aeruginosa (Chakraborty et al., 2021), Vibrio parahaemolyticus (Guo et al., 2019), and Listeria monocytogenes (Liu et al., 2020). However, there are few studies that focus on the inactivation and removal effects of TQ on mature bacterial biofilms. Also, the effect of TQ on A. acidoterrestris vegetative cells, spores, and biofilms is very limited. In this study, the antimicrobial activity and possible mechanism of TQ against $A$. acidoterrestris vegetative cells were explored by MIC determinations, growth curve analysis, time-kill assay, SEM, and confocal laser scanning microscopy (CLSM) observations. Moreover, the effect of TQ on A. acidoterrestris spores was evaluated by viable counts and FESEM observation. And the inactivation and removal efficacy of TQ on A. acidoterrestris biofilms were assessed by viable cell counts and FESEM observation.

\section{MATERIALS AND METHODS}

\section{Reagents}

TQ (HPLC $\geq 99 \%$, CAS 490-91-5) was purchased from Aladdin Biochemical Technology Co., Ltd (Shanghai, China). The commercial compound was dissolved in dimethyl sulfoxide (DMSO) and diluted with sterile deionized water or A. acidoterrestris medium (AAM, $2.0 \mathrm{~g}$ of glucose, $2.0 \mathrm{~g}$ of yeast extract, $1.0 \mathrm{~g}$ of magnesium sulfate, $1.2 \mathrm{~g}$ of potassium dihydrogen phosphate, $0.2 \mathrm{~g}$ of ammonium sulfate, and $0.25 \mathrm{~g}$ of calcium chloride per liter of distilled water) before use. The final concentration of DMSO in all sample solutions was $1 \%(\mathrm{v} / \mathrm{v})$. All other chemicals and reagents were of analytical grade.

\section{Bacterial Strains and Culture Conditions}

The DSM 3922, DSM 3923, and DSM 2498 strains of A. acidoterrestris were purchased from the German Resource Centre for Biological Material (DSMZ). Two other A. acidoterrestris isolates (GYL-02, GYL-11) were obtained from our laboratory strain collection, and originated from the fruit granary of Shaanxi province. Minimum inhibitory concentrations (MICs) determination experiments were conducted for all five A. acidoterrestris strains; however, only DSM 3922 was used in subsequent assays. The strains were stored in AAM broth containing $25 \%(\mathrm{v} / \mathrm{v})$ glycerol at $-80^{\circ} \mathrm{C}$ before use. A. acidoterrestris working suspensions were prepared as follows: First, stock cultures were inoculated onto AAM plates and incubated at $45^{\circ} \mathrm{C}$ for $24 \mathrm{~h}$. Then, the bacterial colony was transferred to AAM broth and incubated at $45^{\circ} \mathrm{C}$ for $12 \mathrm{~h}$ with shaking at $120 \mathrm{rpm}$. Next, the bacterial suspensions were centrifuged $\left(4,000 \times \mathrm{g}, 5 \mathrm{~min}, 4^{\circ} \mathrm{C}\right)$, washed twice with phosphate buffered saline (PBS), and resuspended in sterile AAM broth. Then the optical density of the suspension at $600 \mathrm{~nm}\left(\mathrm{OD}_{600 \mathrm{~nm}}\right)$ was adjusted to 0.5 for use.

To prepare spore suspension, the methods described by Cai et al. (2019b) and Prado et al. (2019) were followed with some modifications. A. acidoterrestris vegetative cells were cultured in AAM broth at $45^{\circ} \mathrm{C}$ for 15 days until about $90 \%$ sporulation was observed under a phase contrast microscopy. Subsequently, the cell culture was centrifuged $\left(4,000 \times \mathrm{g}, 10 \mathrm{~min}, 4^{\circ} \mathrm{C}\right)$, washed twice, and resuspended in cold sterile saline. The spore concentration of the suspension was determined by heat shock $\left(80^{\circ} \mathrm{C}\right.$ for $\left.10 \mathrm{~min}\right)$, serial dilution, and plating on AAM agar, which proved to be $\sim 10^{6}$ spores $/ \mathrm{mL}$. Finally, the suspension was stored at $4^{\circ} \mathrm{C}$ until use. 


\section{MICs Determination}

The MICs of TQ against five A. acidoterrestris strains were measured using a modified version of the broth dilution method, based on the guidelines of the Clinical and Laboratory Standards Institute (Clinical and Laboratory Standards Institute (CLSI), 2009). A. acidoterrestris suspensions $\left(\mathrm{OD}_{600 \mathrm{~nm}} \approx 0.5\right)$ were diluted in AAM broth to achieve the working suspension with a cell concentration of $\sim 10^{5} \mathrm{CFU} / \mathrm{mL}$. Subsequently, the suspension was transferred to a 96-well plate, followed by the addition of TQ solutions. The final concentrations of TQ were 0 (control), 8, 16, 32, 64, 128, 256, and $512 \mu \mathrm{g} / \mathrm{mL}$, respectively. AAM broth containing $1 \%$ DMSO but no TQ was taken as negative control. The plates were incubated at $45^{\circ} \mathrm{C}$ for $24 \mathrm{~h}$, and the lowest concentration at which no visible bacterial growth was observed was considered as the MIC of TQ.

\section{Growth Curves}

A. acidoterrestris DSM 3922 suspensions with an $\mathrm{OD}_{600 \mathrm{~nm}}$ of 0.2 $\left(\sim 3 \times 10^{4} \mathrm{CFU} / \mathrm{mL}\right)$ were inoculated into the wells of a 96-well plate. TQ was added into the corresponding wells to obtain the final concentrations of 0 (control), 1/16 $\times$ MIC, $1 / 8 \times$ MIC, $1 / 4 \times$ MIC, $1 / 2 \times$ MIC, and $1 \times$ MIC, respectively. Then the plate was incubated at $45^{\circ} \mathrm{C}$ for $24 \mathrm{~h}$ and the $\mathrm{OD}_{600 \mathrm{~nm}}$ values were measured by a multimode plate reader (Tecan, Infinite ${ }^{\mathrm{TM}}$ M200 PRO, Mannedorf, Switzerland), at 2-h intervals in order to monitor the growth of $A$. acidoterrestris cells.

\section{Time-kill Assay}

To assess the bactericidal activity of TQ against A. acidoterrestris, the time-kill assay was performed as described by Shi et al. (2016). A. acidoterrestris DSM 3922 suspensions were diluted in AAM broth to a cell concentration of $\sim 10^{5} \mathrm{CFU} / \mathrm{mL}$. TQ was added to the suspensions to achieve final concentrations of 0 (control), $1 / 2 \times$ MIC, $1 \times$ MIC, and $2 \times$ MIC, respectively. Then the samples were incubated at $45^{\circ} \mathrm{C}$ for $0,3,6,9,12$, or $24 \mathrm{~h}$. At each time point, samples were diluted in sterile PBS and spread onto AAM agar for viable enumeration.

\section{Field-Emission Scanning Electron Microscopy (FESEM) Observation}

Following the method of Kang et al. (2019), FESEM observation was conducted with slight modifications. Briefly, A. acidoterrestris cells treated with TQ $(0,1 \times \mathrm{MIC}$, and $2 \times \mathrm{MIC})$ were incubated at $45^{\circ} \mathrm{C}$ for $2 \mathrm{~h}$, followed by centrifugation $\left(3,000 \times \mathrm{g}, 5 \mathrm{~min}, 4^{\circ} \mathrm{C}\right)$ and washing twice with PBS. The A. acidoterrestris cells were fixed with $2.5 \%$ glutaraldehyde at $4^{\circ} \mathrm{C}$ for $12 \mathrm{~h}$ and dehydrated with $30,50,70,80,90$, and $100 \%$ water-ethanol solutions for $10 \mathrm{~min}$, respectively. After critical point drying and gold spray treatment, samples were observed using a field-emission scanning electron microscope (Nano SEM-450, FEI, United States).

\section{Confocal Laser Scanning Microscopy (CLSM) Observation}

CLSM observation was carried out according to the method described by Song et al. (2019), with minor modifications.
A. acidoterrestris DSM 3922 suspensions treated with TQ (0, $1 \times \mathrm{MIC}$, and $2 \times \mathrm{MIC}$ ) were incubated at $45^{\circ} \mathrm{C}$ for $60 \mathrm{~min}$. Then the suspensions were centrifuged $(3,000 \times \mathrm{g}, 5 \mathrm{~min}$, $4^{\circ} \mathrm{C}$ ) and resuspended with $0.85 \%$ sterile saline. Following the addition of propidium iodide (PI) and SYTO 9, the suspensions were incubated in the dark for $15 \mathrm{~min}$. Finally, the samples were deposited on a glass slide for CLSM analysis at the excitation/emission wavelengths of 480/500 nm (SYTO 9) and $490 / 635 \mathrm{~nm}(\mathrm{PI})$.

\section{Spore Inactivation Assay}

With slight modifications, the method of Prado et al. (2019) was used in this assay. Briefly, A. acidoterrestris spore suspensions (stored at $4^{\circ} \mathrm{C}$ for about 1 month) were diluted with $0.85 \%$ sterile saline to achieve a cell density of $10^{4} \sim 10^{5} \mathrm{CFU} / \mathrm{mL}$. TQ was then added to obtain final concentrations of 0 (control), $4 \times$ MIC, $8 \times$ MIC, and $16 \times$ MIC, respectively. The spores in the control group were not treated with TQ. Then samples were incubated at $45^{\circ} \mathrm{C}$ for $0,30,60,120,180,240$, or $360 \mathrm{~min}$. At each time point, samples were taken, diluted, and spread onto AAM agar, followed by incubation and viable counts.

\section{FESEM Observation of Spores}

To confirm the inactivation effect of TQ on spores, the morphology of TQ-treated spores was observed using FESEM. The spore suspensions mentioned above were treated with TQ $(0,4 \times \mathrm{MIC}, 8 \times \mathrm{MIC}$, and $16 \times \mathrm{MIC})$ at $45^{\circ} \mathrm{C}$ for $6 \mathrm{~h}$. Samples were centrifuged at $4,000 \times \mathrm{g}$ at $4^{\circ} \mathrm{C}$ for $10 \mathrm{~min}$ and the cells were fixed with $2.5 \%$ glutaraldehyde. The following gradient dehydration, critical point drying, gold spray treatment, and FESEM observations were the same as described in above section.

\section{Biofilm Inactivation Assay Inactivation of Biofilms Formed on a Polystyrene Microplate}

According to the method by Fan et al. (2018), the effect of TQ on A. acidoterrestris biofilms formed on a polystyrene microplate was explored with some modifications. A. acidoterrestris DSM 3922 suspensions were inoculated into a 96-well flat-bottomed plate, and incubated at $45^{\circ} \mathrm{C}$ for $24 \mathrm{~h}$ to form biofilms. The AAM broth in wells were abandoned, and each well was gently rinsed with PBS. TQ solutions (prepared in AAM broth) at the concentrations of 0 (control), $2 \times \mathrm{MIC}, 4 \times \mathrm{MIC}$, and $8 \times \mathrm{MIC}$ were added, and the plate was incubated at $45^{\circ} \mathrm{C}$ for $0,30,60,90$, 120 , or $180 \mathrm{~min}$. At each time point, the sample in each well was mixed thoroughly and then serially diluted in sterile PBS. One hundred microliters of the PBS suspension was spread onto AAM agar and the plates were incubated at $45^{\circ} \mathrm{C}$ for $24 \mathrm{~h}$. The viable bacterial counts were expressed as $\log \mathrm{CFU} / \mathrm{mL}$.

\section{Inactivation of Biofilms Formed on a Stainless Steel Surface}

Brifely, A. acidoterrestris DSM 3922 suspensions were added into sterile tubes with $1 \mathrm{~mL}$ per tube, followed by the addition of stainless steel sheets $(1 \mathrm{~cm} \times 1 \mathrm{~cm})$ which had been cleaned by ultrasonication and sterilized with steam. Then samples were incubated at $45^{\circ} \mathrm{C}$ for $24 \mathrm{~h}$. The sheets were gently rinsed 
with PBS and carefully transferred to new tubes containing TQ solutions of 0 (control), $2 \times \mathrm{MIC}, 4 \times \mathrm{MIC}$, and $8 \times \mathrm{MIC}$. After that, samples were incubated at $45^{\circ} \mathrm{C}$ for $0,30,60,90$, 120 , or $180 \mathrm{~min}$. At each time point, $1 \mathrm{~g}$ of sterile glass beads ( $1 \mathrm{~mm}$, Glastechnique Mfg., Germany) was added into the tube and vortexed for $5 \mathrm{~min}$ (Kim et al., 2019; Huang et al., 2020). The resulting suspension was serially diluted with sterile PBS, followed by plating spread, incubation, and enumeration.

\section{Biofilm Removal Assay}

With minor modifications, the method described by Fan et al. (2018) was followed. A. acidoterrestris DSM 3922 suspensions were co-incubated with sterile stainless steel sheets $(5 \mathrm{~mm} \times 5 \mathrm{~mm})$ in a sterile 24-well flat-bottomed plate at $45^{\circ} \mathrm{C}$ for $24 \mathrm{~h}$. The sheets were gently rinsed with PBS and carefully transferred to the new wells containing TQ solutions at 0 (control), $2 \times$ MIC, $4 \times$ MIC, and $8 \times$ MIC. After an incubation at $45^{\circ} \mathrm{C}$ for $4 \mathrm{~h}$, the sheets were washed gently with PBS before being immersed in a $2.5 \%$ glutaraldehyde solution for fixing. The following gradient dehydration, critical point drying, gold spray treatment, and FESEM analysis were conducted as described in the above section.

\section{Statistical Analyses}

The IBM SPSS software (New York, United States) was used for statistical analysis. All experiments were performed three times, and the data were expressed as mean \pm standard deviation. The differences between means were tested by two-way analysis of variance and were considered significant at $p<0.05$.

\section{RESULTS}

\section{MICs}

As shown in Table 1, the MICs of TQ against five A. acidoterrestris strains ranged from 32 to $64 \mu \mathrm{g} / \mathrm{mL}$. The results suggested that TQ was effective at inhibiting $A$. acidoterrestris and may be used as a potential method to control $A$. acidoterrestris in the food industry.

\section{Growth Curve Analyses}

The effect of TQ on the growth of A. acidoterrestris DSM 3922 is presented in Figure 1A. In the presence of TQ $(1 \times \mathrm{MIC})$, the $\mathrm{OD}_{600 \mathrm{~nm}}$ of the $A$. acidoterrestris suspension remained steady within $24 \mathrm{~h}$, suggesting that this concentration of TQ

TABLE 1 | Minimum inhibitory concentrations (MICs) of TQ against A. acidoterrestris strains.

\begin{tabular}{llc}
\hline Strains & Origins & MICs $(\boldsymbol{\mu} \mathbf{g} / \mathbf{m l})$ \\
\hline DSM 3922 & DSM & 32 \\
DSM 3923 & DSM & 32 \\
DSM 2498 & DSM & 32 \\
GYL-02 & Fruit granary & 64 \\
GYL-11 & Fruit granary & 32 \\
\hline
\end{tabular}

DSM, German Resource Centre for Biological Material. inhibited the growth of $A$. acidoterrestris. In the presence of TQ $(1 / 4 \times \mathrm{MIC}, 1 / 8 \times \mathrm{MIC}$, and $1 / 16 \times \mathrm{MIC})$, the $\mathrm{OD}_{600 \mathrm{~nm}}$ of the A. acidoterrestris suspension increased continuously over time, indicating that TQ at these concentrations could not inhibit the bacterial growth.

\section{Time-Kill Curves}

The bactericidal effect of TQ on A. acidoterrestris DSM 3922 is shown in Figure 1B. The initial number of $A$. acidoterrestris cells in the samples was $4.8 \log \mathrm{CFU} / \mathrm{mL}$. Viable cells counts in the group treated with TQ $(1 / 2 \times \mathrm{MIC})$ decreased to $4.4 \log \mathrm{CFU} / \mathrm{mL}$ and then increased continually to $7.1 \log \mathrm{CFU} / \mathrm{mL}$. In contrast, the number of cells in groups exposed to TQ $(1 \times$ MIC and $2 \times$ MIC) reduced constantly over time. At $3 \mathrm{~h}$ post-treatment, TQ at $1 \times$ MIC and $2 \times$ MIC reduced the cell counts to 3.5 and $2.6 \log \mathrm{CFU} / \mathrm{mL}$, respectively. And at $24 \mathrm{~h}$ post-treatment, TQ at the two concentrations caused greater reductions to 2.9 and $1.8 \log \mathrm{CFU} / \mathrm{mL}$, respectively. The results revealed that TQ at $1 \times$ MIC and $2 \times$ MIC exerted a bactericidal effect on A. acidoterrestris cells.

\section{FESEM Observation}

The changes in A. acidoterrestris cell morphology caused by TQ were confirmed by FESEM observation. As shown in Figure 2, untreated $A$. acidoterrestris cells were regular, smooth, plump, and rod-shaped. Whereas after exposure to TQ $(1 \times \mathrm{MIC}$ and $2 \times \mathrm{MIC}$ ) for $2 \mathrm{~h}$, the surfaces of the A. acidoterrestris cells became rough, irregular, and wrinkled. Moreover, perforations and cankers were observed. The results revealed that TQ at $1 \times$ MIC and $2 \times$ MIC destroyed the cell morphology of A. acidoterrestris.

\section{CLSM Observation}

The damage of TQ to A. acidoterrestris membrane integrity was assessed using fluorescent dyes SYTO 9 and PI by CLSM observation. SYTO 9 is a nucleic acid dye which can penetrate all bacterial cells, combine with DNA, and generate green fluorescence. By contrast, PI only stains the bacterial cells that have a damaged cell membrane and it generates red fluorescence. As presented in Figure 3, A. acidoterrestris cells in the control group exhibited complete green fluorescence and almost no red fluorescence was observed, suggesting that cells in this group had an intact membrane. In contrast, a small amount of red fluorescence occurred after treatment with TQ at $1 \times \mathrm{MIC}$, indicating that the membrane integrity of some cells was destroyed by TQ. After exposure to TQ at $2 \times$ MIC, a dramatic increase in red fluorescence intensity was observed, showing that this concentration of TQ resulted in a more damaged cell membrane. Overall, these findings demonstrated that TQ could impair the cell membrane of A. acidoterrestris in a dosedependent manner.

\section{Spore Inactivation}

The killing effect of TQ $(0,4 \times \mathrm{MIC}, 8 \times \mathrm{MIC}$, and $16 \times \mathrm{MIC})$ on $A$. acidoterrestris spores is shown in Figure 4. The number of spores at $0 \mathrm{~min}$ in all samples were $4.7 \log \mathrm{CFU} / \mathrm{mL}$. Obviously, 

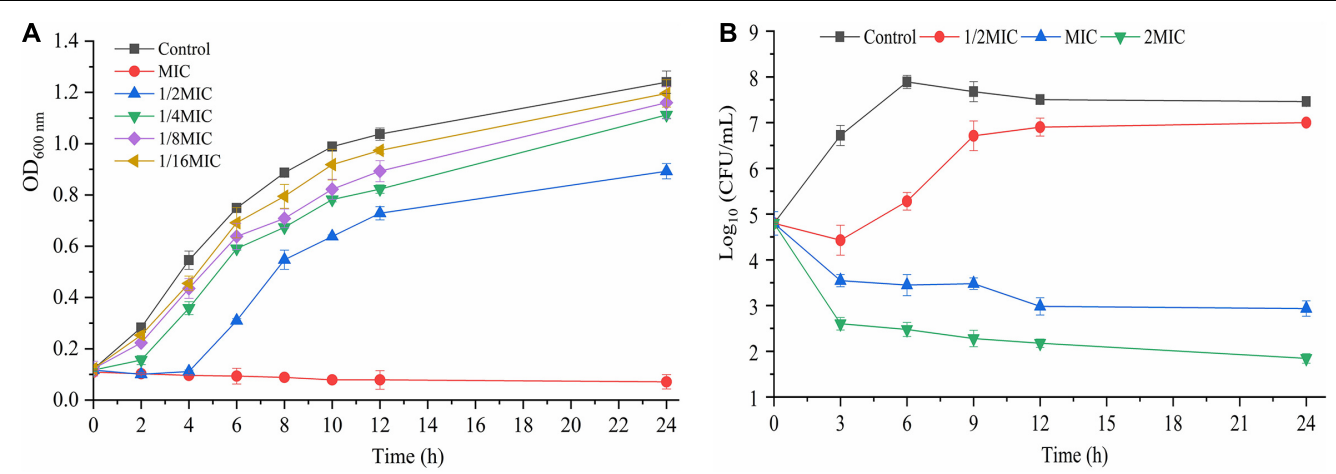

FIGURE 1 | Growth curves (A) of $A$. acidoterrestris DSM 3922 in the presence of TQ $(1 \times$ MIC 1/16 $\times$ MIC). Time-kill curves (B) of TQ $(0,1 / 2 \times$ MIC, $1 \times$ MIC, and $2 \times \mathrm{MIC}$ ) against $A$. acidoterrestris DSM 3922 in AAM broth. Error bars represent standard deviation of three replicates. OD $600 \mathrm{~nm}$, optical density at $600 \mathrm{~nm}$.
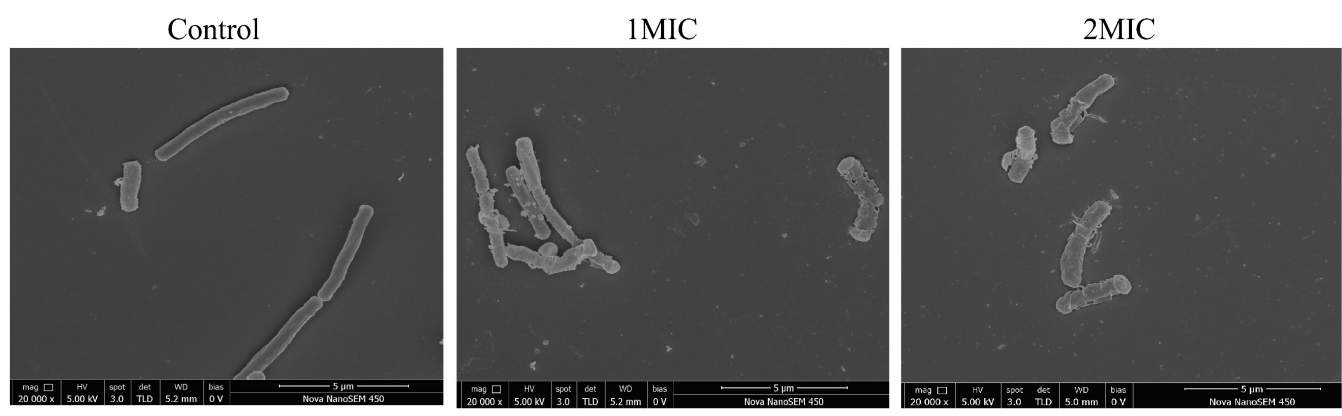

FIGURE 2 | Scanning electronic images of $A$. acidoterrestris DSM 3922 after exposure to TQ of 0 (control), $1 \times$ MIC and $2 \times$ MIC for $2 \mathrm{~h}$.
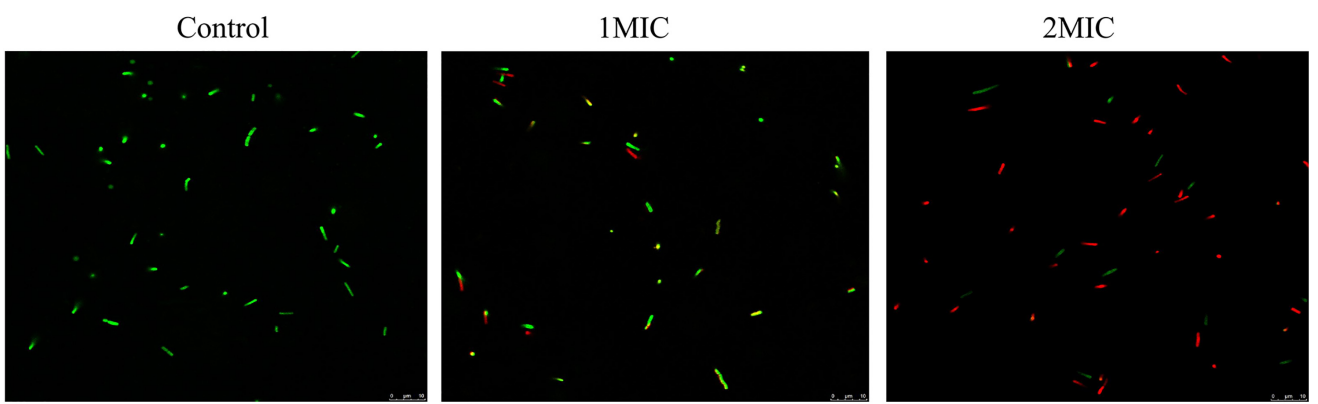

FIGURE 3 | Confocal laser scanning microscopy images of $A$. acidoterrestris DSM 3922 after treatment with TQ of 0 (control), $1 \times$ MIC and $2 \times$ MIC for 60 min Scale bar: $10 \mu \mathrm{m}$.

the number of spores in the untreated group remained the same throughout the experiment, while the number of spores in the TQ-treated groups decreased over time. At $240 \mathrm{~min}$ posttreatment, TQ $(4 \times$ MIC, $8 \times$ MIC, and $16 \times$ MIC) reduced the spore counts to $4.4,4.0$, and $3.8 \log \mathrm{CFU} / \mathrm{mL}$, respectively. And greater reductions to $4.2,3.8$, and $3.5 \log \mathrm{CFU} / \mathrm{mL}$ were achieved at $360 \mathrm{~min}$ post-treatment. The results revealed that TQ exerted a moderate inactivation effect on A. acidoterrestris spores.

\section{FESEM Observation of Spores}

The effect of TQ on A. acidoterrestris spores was further verified by FESEM observation. As presented in Figure 5, untreated spores exhibited a normal morphology with an oval, smooth, and plump shape. After exposure to TQ $(4 \times \mathrm{MIC})$ for $6 \mathrm{~h}$, the surface of spores became rough, wrinkled, or even hollow. Moreover, rupturing and cracks occurred on the surface as the concentration of TQ increased to $8 \times$ MIC and $16 \times$ MIC.

\section{Biofilm Inactivation}

The inactivation effects of TQ on A. acidoterrestris biofilms formed on polystyrene and stainless steel surfaces are shown in Figures 6A,B. Obviously, TQ treatments reduced the number of viable cells in biofilms formed on the two surfaces. The initial number of $A$. acidoterrestris cells on biofilms formed on the 


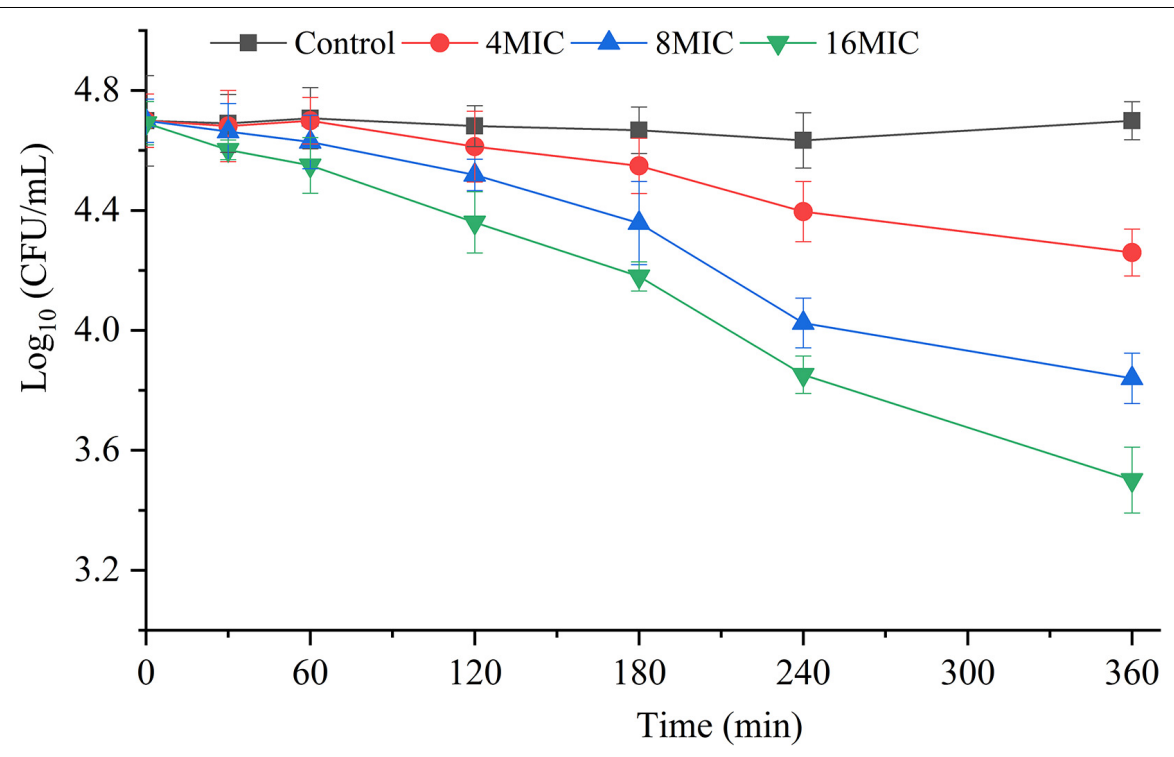

FIGURE 4 | Inactivation effect of TQ on A. acidoterrestris spores. The spores were treated with TQ at the concentrations of 0 (control), $4 \times$ MIC, $8 \times$ MIC, and $16 \times$ MIC for $360 \mathrm{~min}$. Error bars represent standard deviation of three replicates.
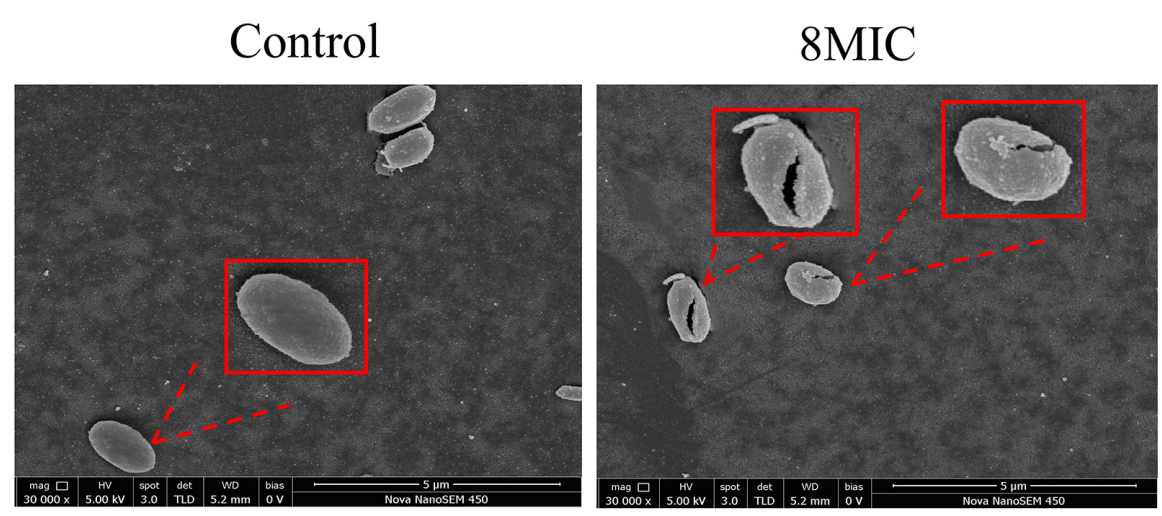

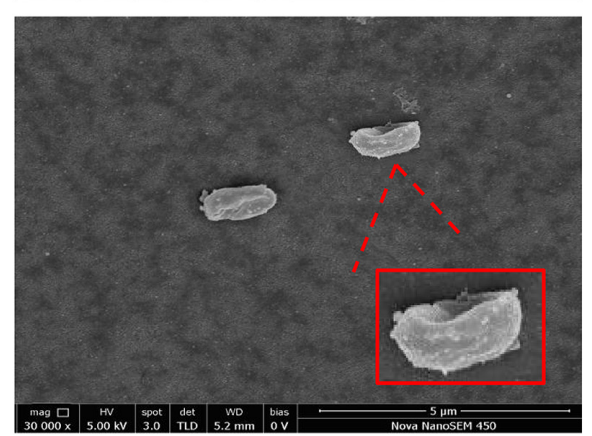

$4 \mathrm{MIC}$

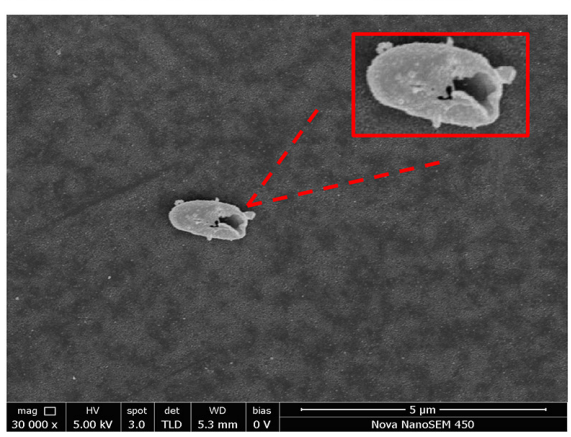

$16 \mathrm{MIC}$

FIGURE 5 | Scanning electronic images of $A$. acidoterrestris DSM 3922 spores after treatment with TQ of 0 (control), $4 \times$ MIC, $8 \times$ MIC, and $16 \times$ MIC for 6 h.

polystyrene surface was $5.5 \log \mathrm{CFU} / \mathrm{ml}$ and decreased to $4.9,3.8$, $3.0 \log \mathrm{CFU} / \mathrm{ml}, 4.8,3.4,2.6 \log \mathrm{CFU} / \mathrm{ml}$, and 4.6, 2.9, $1.9 \log$ $\mathrm{CFU} / \mathrm{ml}$ after treatment with TQ $(2 \times$ MIC, $4 \times$ MIC, $8 \times$ MIC $)$ for 60,120 , and $180 \mathrm{~min}$, respectively. Similarly, TQ reduced the number of A. acidoterrestris cells in biofilms formed on the stainless steel surface. At the initiation of treatment, the total number of viable A. acidoterrestris cells on stainless steel surfaces was $5.9 \log \mathrm{CFU} / \mathrm{ml}$. Whereas at 60,120 , and $180 \mathrm{~min}$ posttreatment of TQ $(2 \times$ MIC, $4 \times$ MIC, $8 \times$ MIC), viable counts in the biofilms were reduced to 5.6, 5.1, $4.5 \log \mathrm{CFU} / \mathrm{ml}, 5.0,4.4$, 

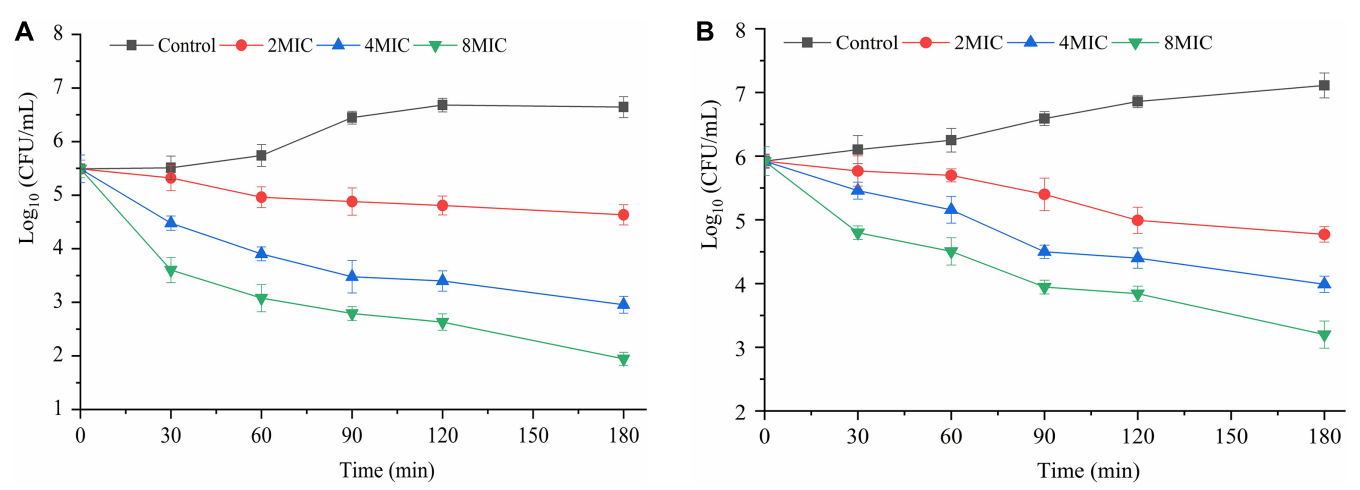

FIGURE 6 | Inactivation effect of TQ on A. acidoterrestris DSM 3922 biofilms grown in AAM broth at $45^{\circ} \mathrm{C}$ for $24 \mathrm{~h}$ on polystyrene (A) and stainless steel (B) surfaces. Formed biofilms were treated with TQ at the concentrations of 0 (control), $2 \times \mathrm{MIC}, 4 \times \mathrm{MIC}$, and $8 \times \mathrm{MIC}$ for 180 min. Error bars represent standard deviation of three replicates.

$3.8 \log \mathrm{CFU} / \mathrm{ml}$, and 4.7, 3.9, $3.2 \log \mathrm{CFU} / \mathrm{ml}$, respectively. The results indicated that TQ could inactivate $A$. acidoterrestris cells on biofilms developed on polystyrene and stainless steel surfaces in a concentration-dependent manner.

\section{Biofilm Removal}

The elimination effect of TQ on A. acidoterrestris biofilms was confirmed by FESEM observation and the images are presented in Figure 7. A. acidoterrestris biofilms in the control group were dense, evenly distributed, and had a multilayer structure with clustered cells. Nevertheless, at $4 \mathrm{~h}$ post-treatment of TQ $(2 \times$ MIC and $4 \times \mathrm{MIC})$, the layer became thin, uneven, and the cell clusters in the biofilm decreased. After treatment with TQ at $8 \times$ MIC, the number of $A$. acidoterrestris cells adhered to the surface decreased significantly and no $A$. acidoterrestris clusters were observed. The results suggested that TQ may be applied as an antibiofilm agent in the food industry to control A. acidoterrestris biofilms.

\section{DISCUSSION}

In this study, TQ was demonstrated to possess good antimicrobial activity against $A$. acidoterrestris vegetative cells with MICs ranging from 32 to $64 \mu \mathrm{g} / \mathrm{mL}$. In recent years, natural compounds with antibacterial activity have garnered great attention as an efficient means of fighting bacteria. Many natural compounds has been reported to show an inhibitory effect on A. acidoterrestris, such as paracin C, pomegranate fruit extract, rosemary extracts, and lemon essential oil (Cristina Maldonado et al., 2013; Molva and Baysal, 2015; Piskernik et al., 2016; Pei et al., 2017). Also, previous studies demonstrated that Piper marginatum extracts, thymol, cinnamic acid, and chlorogenic acid had the ability to inhibit growth of $A$. acidoterrestris with MICs of $62.5,250,375$, and 2,000 $\mu \mathrm{g} / \mathrm{mL}$ (de Pascoli et al., 2018; Cai et al., 2019a,b). Obviously, TQ showed a stronger inhibitory activity against $A$. acidoterrestris than most of the reported compounds. From growth curves, we can easily see that the cell density of samples treated with TQ at $1 \times$ MIC was almost unchanged over time (Figure 1A), suggesting that the treatment completely suppressed the growth of A. acidoterrestris DSM 3922 cells. Similarly, the time-kill curves in Figure 1B showed that the number of bacterial cells decreased significantly after exposure to TQ at $1 \times$ MIC. Therefore, TQ $(1 \times$ MIC) also has a bactericidal effect on A. acidoterrestris DSM 3922.

Normal cell morphology and an intact cell membrane are essential for bacteria to stay alive and maintain various physiological metabolism activities. At present, natural products from different sources are a research hotspot in the antibacterial field, and have great potential as novel bacteriostats and bactericides. Many natural compounds were demonstrated to exert antibacterial activity by destroying cell morphology and membrane integrity. Xu et al. (2017) investigated the effect of punicalagin on Staphylococcus aureus morphology using scanning and transmission electron microscopy, and found that abnormal cell morphology (the enlarged size and rough surface) occurred after the treatment of punicalagin at $0.5 \mathrm{mg} / \mathrm{mL}$. Sun et al. (2020) proved that chlorogenic acid induced the cell envelope damage of Salmonella Enteritidis by scanning electron microscopy observation. And further CLSM examination demonstrated that the inner membrane was also disrupted by chlorogenic acid. In this study, TQ at the concentration of MIC and 2MIC (32 and $64 \mu \mathrm{g} / \mathrm{mL}$ ) induced abnormal morphology of $A$. acidoterrestris, destroyed the integrity of the cell membrane, and thus resulted in growth inhibition and cell death (Figures 2, 3).

A. acidoterrestris is a spore-former, and the strong resistance of its spores to high temperature and other adverse environments, such as low $\mathrm{pH}$ conditions, has make the bacterium a challenge in the quality control of pasteurized juices and beverages (Jovetta et al., 2011). Therefore, many strategies have been explored by scholars to control A. acidoterrestris spores, including chemical and physical methods. In the present study, TQ was proved to inactivate spores at the concentrations of $4 \times \mathrm{MIC}$, $8 \times \mathrm{MIC}$, and $16 \times \mathrm{MIC}(128,256$, and $512 \mu \mathrm{g} / \mathrm{mL})$ (Figure 4). Moreover, TQ treatment altered the morphology of spores and rendered their surfaces rough, hollow, and cracked 

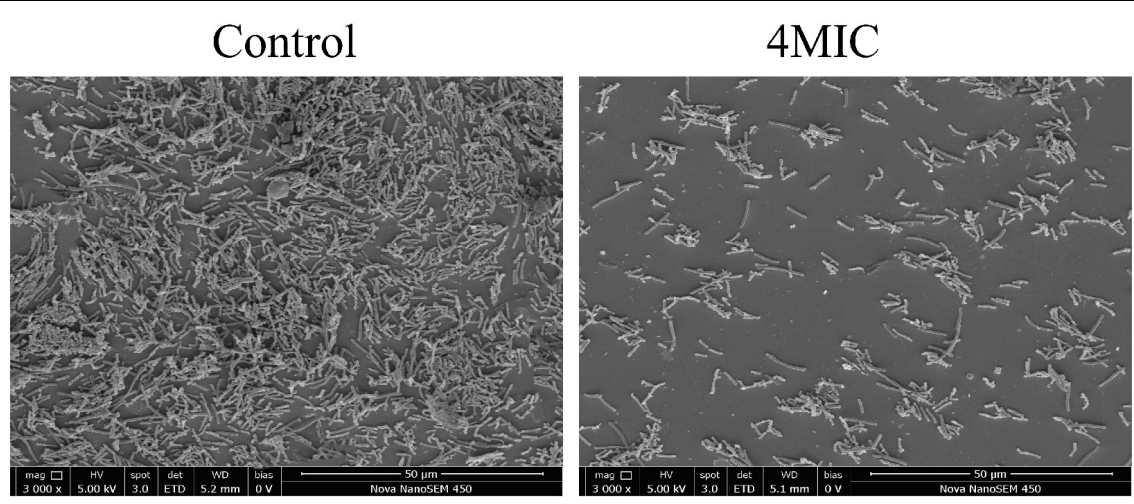

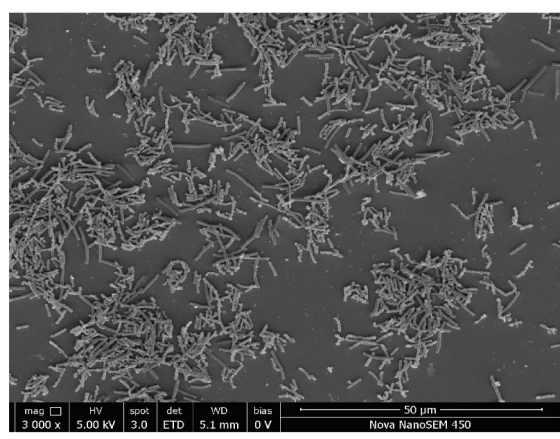

2MIC

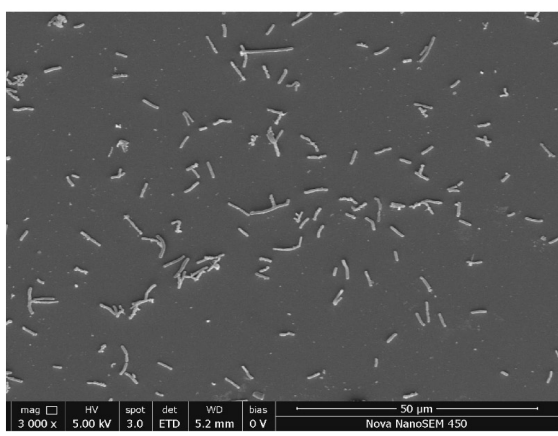

8MIC

FIGURE 7 | Scanning electronic images of $A$. acidoterrestris DSM 3922 biofilms after exposure to TQ of 0 (control), $2 \times$ MIC, $4 \times$ MIC, and $8 \times$ MIC for 4 h.

(Figure 5). Similarly, Cai et al. (2019b) demonstrated that thymol was able to inhibit and inactivate $A$. acidoterrestris spores, with an MIC and MBC of $0.5 \mathrm{mg} / \mathrm{mL}$ and greater than $1.0 \mathrm{mg} / \mathrm{mL}$, respectively. Prado et al. (2019) reported that $A$. acidoterrestris spores counts were reduced by $3 \log$ $\mathrm{CFU} / \mathrm{mL}$ after exposure to ultraviolet $\mathrm{C}$ radiation from 5 to 15 min. Besides, like TQ, ultraviolet $\mathrm{C}$ radiation $\left(12.6 \mathrm{~kJ} / \mathrm{m}^{2}\right)$ produced visible morphological changes in $A$. acidoterrestris spores such as distortions, central depression, and expressive roughness. In addition to single chemical and physical methods, combinations of these methods were also used to control A. acidoterrestris spores. For example, Huertas et al. (2014) demonstrated that the inactivation effects of nisin and citral on A. acidoterrestris spores were enhanced by heat. Similarly, high pressure processing pretreatment promoted the inactivation of $A$. acidoterrestris spores by thermo-sonication (Evelyn and Silva, 2016). Based on these findings, we proposed to study the synergistic spore-inactivation effects of combinations of TQ with different physical methods, such as ozone, ultrasound, thermal treatment, ultraviolet radiation, and high pressure treatments.

A. acidoterrestris was able to form biofilms on the surfaces of food processing facilities, such as stainless steel, glass, and nylon (dos Anjos et al., 2013; Shemesh et al., 2014). Traditionally, chemical disinfectants have been the primary method to control bacterial biofilms. Nevertheless, the safety and residue of these sanitizers went against people's health concepts and become increasingly unaccepted (Fan et al., 2018).
On the contrary, natural compounds possessing antibiofilm activity are attracting a growing amount of attention. According to previous studies, some natural compounds can inhibit the formation of these biofilms. For example, clove essential oil $(0.05 \%)$ can reduce the formation of $A$. acidoterrestris biofilms on glass and polyvinyl chloride surfaces by $25.1 \sim 65.0 \%$ (KunickaStyczyńska et al., 2020). Consistently, ultraviolet C radiation was proven to exhibit an inhibitory effect on $A$. acidoterrestris biofilms formation on stainless steel and rubber surfaces, and also an inactivation effect on a biofilm formed on two surfaces (Prado et al., 2019). Besides, an earlier study proved the bactericidal efficacy of three sanitizers (peracetic acid, sodium hypochlorite, and quaternary ammonia) on $A$. acidoterrestris biofilms formed on stainless steel, polyvinyl chloride, and nylon surfaces (dos Anjos et al., 2013). However, literature concerning inactivation and elimination of $A$. acidoterrestris biofilms by natural compounds is very limited. In the current study, TQ, at $2 \times$ MIC, $4 \times$ MIC, and $8 \times$ MIC, was demonstrated to be effective in inactivating and removing $A$. acidoterrestris biofilms on polystyrene and stainless steel surfaces, and resulted in reductions of $2.0 \sim 4.7$ and 2.5 3.6 $\log \mathrm{CFU} / \mathrm{mL}$ after 180min treatment, compared with the control group (Figures 6, 7). These results suggested that TQ can be used as a natural agent to control and eliminate $A$. acidoterrestris biofilms formed on polystyrene plastic and stainless steel surfaces in the food production line. Further studies are required to explore other natural compounds that possess antibiofilm activity against A. acidoterrestris. 


\section{CONCLUSION}

In conclusion, TQ showed good antibacterial activity against A. acidoterrestris vegetative cells with MICs of $32 \sim 64 \mu \mathrm{g} / \mathrm{mL}$. TQ exerted its antimicrobial and bactericidal activity by delaying bacterial growth, altering cell morphology (shrinkage, perforation, and canker), and destroying the cytoplasmic membrane. In addition, TQ showed a moderate killing effect on $A$. acidoterrestris spores and was effective in inactivating A. acidoterrestris biofilms formed on polystyrene and stainless steel surfaces as well as in removing A. acidoterrestris biofilms. These findings demonstrate that TQ has the potential to be an effective antimicrobial and antibiofilm agent to control contamination and deterioration caused by A. acidoterrestris.

\section{DATA AVAILABILITY STATEMENT}

The original contributions presented in the study are included in the article/supplementary material,

\section{REFERENCES}

Abdelrazek, H. M. A., Kilany, O. E., Muhammad, M. A. A., Tag, H. M., and Abdelazim, A. M. (2018). Black seed thymoquinone improved insulin secretion, hepatic glycogen storage, and oxidative stress in streptozotocininduced diabetic male wistar rats. Oxid. Med. Cell. Longev. 2018, 1-10. doi: $10.1155 / 2018 / 8104165$

Aziz, A. E. A. E., Sayed, N. S. E., and Mahran, L. G. (2011). Anti-asthmatic and anti-allergic effects of thymoquinone on airway-induced hypersensitivity in experimental animals. J. App. Pharm. Sci. 1, 109-117.

Basson, A., Flemming, L. A., and Chenia, H. Y. (2007). Evaluation of adherence, hydrophobicity, aggregation, and biofilm development of Flavobacterium johnsoniae-like isolates. Microb. Ecol. 55, 1-14. doi: 10.1007/s00248-007-9 245-y

Cai, R., Miao, M., Yue, T., Zhang, Y., Cui, L., Wang, Z., et al. (2019a). Antibacterial activity and mechanism of cinnamic acid and chlorogenic acid against Alicyclobacillus acidoterrestris vegetative cells in apple juice. Int. J. Food Sci. Tech. 54, 1697-1705. doi: 10.1111/ijfs.14051

Cai, R., Yuan, Y., Wang, Z., Guo, C., Liu, B., Liu, L., et al. (2015). Precursors and metabolic pathway for guaiacol production by Alicyclobacillus acidoterrestris. Int. J. Food Microbiol. 214, 48-53. doi: 10.1016/j.ijfoodmicro.2015. 07.028

Cai, R., Zhang, M., Cui, L., Yuan, Y., Yang, Y., Wang, Z., et al. (2019b). Antibacterial activity and mechanism of thymol against Alicyclobacillus acidoterrestris vegetative cells and spores. LWT Food Sci. Technol. 105, 377-384. doi: 10.1016/ j.lwt.2019.01.066

Chakraborty, P., Paul, P., Kumari, M., Bhattacharjee, S., Singh, M., Maiti, D., et al. (2021). Attenuation of Pseudomonas aeruginosa biofilm by thymoquinone: an individual and combinatorial study with tetrazine-capped silver nanoparticles and tryptophan. Folia Microbiol. 66, 255-271. doi: 10.1007/s12223-020-00 841-1

Chehl, N., Chipitsyna, G., Gong, Q., Yeo, C. J., and Arafat, H. A. (2009). Anti-inflammatory effects of the Nigella sativa seed extract, thymoquinone, in pancreatic cancer cells. HPB 11, 373-381. doi: 10.1111/j.1477-2574.2009.0 0059.x

Chen, S., Tang, Q., Zhang, X., Zhao, G., Hu, X., Liao, X., et al. (2006). Isolation and characterization of thermo-acidophilic endospore-forming bacteria from the concentrated apple juice-processing environment. Food Microbiol. 23, 439-445. doi: 10.1016/j.fm.2005.07.005

Clinical and Laboratory Standards Institute (CLSI) (2009). Clinical and Laboratory Standards Institute CLSI; CLSI publishes 2009 antimicrobial susceptibility testing standards. Atlanta, 12. further inquiries can be directed to the corresponding author/s.

\section{AUTHOR CONTRIBUTIONS}

QF, YY, and TY conceived and designed the experiments. QF, $\mathrm{CL}$, and $\mathrm{ZW}$ performed the experiments. ZG and $\mathrm{ZH}$ analyzed the data. JX contributed to reagents and materials. QF wrote the manuscript. YY and TY provided funding acquisition. All authors read and approved the manuscript.

\section{FUNDING}

This work was supported partly by the National Key Research and Development Project During the 13th 5-Year Plan (2019YFC1606700).
Cristina Maldonado, M., Paola Aban, M., and Roberto Navarro, A. (2013). Chemicals and lemon essential oil effect on Alicyclobacillus acidoterrestris viability. Braz. J. Microbiol. 44, 1133-1137. doi: 10.1590/ S1517-83822013000400015

de Pascoli, I. C., dos Anjos, M. M., da Silva, A. A., Lorenzetti, F. B., Cortez, D. A. G., Mikcha, J. M. G., et al. (2018). Piperaceae extracts for controlling Alicyclobacillus acidoterrestris growth in commercial orange juice. Crop Prod. 116, 224-230. doi: 10.1016/j.indcrop.2018.02.073

dos Anjos, M. M., Ruiz, S. P., Nakamura, C. V., and de Abreu, B. A. (2013). Resistance of Alicyclobacillus acidoterrestris spores and biofilm to industrial sanitizers. J. Food Prot. 76, 1408-1413. doi: 10.4315/0362-028x.Jfp-13-020

Driks, A., Zhang, J., Yue, T., and Yuan, Y. (2013). Alicyclobacillus contamination in the production line of kiwi products in China. PLoS One 8:e67704. doi: 10.1371/journal.pone.0067704

Evelyn, E., and Silva, F. V. M. (2016). High pressure processing pretreatment enhanced the thermosonication inactivation of Alicyclobacillus acidoterrestris spores in orange juice. Food Control 62, 365-372. doi: 10.1016/j.foodcont.2015. 11.007

Fan, Q., Zhang, Y., Yang, H., Wu, Q., Shi, C., Zhang, C., et al. (2018). Effect of coenzyme Q0 on biofilm formation and attachment-invasion efficiency of Listeria monocytogenes. Food Control 90, 274-281. doi: 10.1016/j.foodcont. 2018.02.047

Forouzanfar, F., Bazzaz, B. S. F., and Hosseinzadeh, H. (2014). Black cumin (Nigella sativa) and its constituent (thymoquinone): a review on antimicrobial effects. Iran. J. Basic Med. Sci. 17, 929-938.

Guo, D., Yang, Z., Zheng, X., Kang, S., Yang, Z., Xu, Y., et al. (2019). Thymoquinone inhibits biofilm formation and attachment-invasion in host cells of Vibrio parahaemolyticus. Foodborne Pathog. Dis. 16, 671-678. doi: 10.1089/fpd.2018. 2591

Huang, X., Yuan, Y., Guo, C., Gekas, V., and Yue, T. (2015). Alicyclobacillus in the fruit juice industry: spoilage, detection, and prevention/control. Food Rev. Int. 31, 91-124. doi: 10.1080/87559129.2014.974266

Huang, Y., Pei, Q., Deng, R., Zheng, X., Guo, J., Guo, D., et al. (2020). Inactivation efficacy of $405 \mathrm{~nm}$ LED against Cronobacter sakazakii biofilm. Front. Microbiol 11:610077. doi: 10.3389/fmicb.2020.610077

Huertas, J. P., Esteban, M. D., Antolinos, V., and Palop, A. (2014). Combined effect of natural antimicrobials and thermal treatments on Alicyclobacillus acidoterrestris spores. Food Control 35, 73-78. doi: 10.1016/j.foodcont.2013.06. 051

Jovetta, M. P., Augusto, P. E. D., Tribst, A. A. L., Conti, M. J., and Cristianini, M. (2011). Thermal Inactivation of Alicyclobacillus acidoterrestris in a model food. Int. J. Food Eng 7, 1-11. doi: 10.2202/1556-3758.1996 
Kang, J., Jin, W., Wang, J., Sun, Y., Wu, X., and Liu, L. (2019). Antibacterial and anti-biofilm activities of peppermint essential oil against Staphylococcus aureus. LWT Food Sci. Technol. 101, 639-645. doi: 10.1016/j.lwt.2018.11.093

Keiichi and GOTO (2006). Thermophilic, acidophilic spore-forming bacilli, Alicyclobacillus, and spoilage of acidic beverages. Japan. J. Food Microbiol. 23, 204-212. doi: 10.5803/jsfm.23.204

Kim, Y., Kim, H., Beuchat, L. R., and Ryu, J. H. (2019). Inhibition of Listeria monocytogenes using biofilms of non-pathogenic soil bacteria (Streptomyces spp.) on stainless steel under desiccated condition. Food Microbiol. 79, 61-65. doi: 10.1016/j.fm.2018.11.007

Kunicka-Styczyńska, A., Tyfa, A., Laskowski, D., Plucińska, A., Rajkowska, K., and Kowal, K. (2020). Clove oil (Syzygium aromaticum L.) activity against Alicyclobacillus acidoterrestris biofilm on technical surfaces. Molecules 25:3334. doi: 10.3390/molecules25153334

Liu, Y., Wu, L., Han, J., Dong, P., Luo, X., Zhang, Y., et al. (2020). Inhibition of biofilm formation and related gene expression of Listeria monocytogenes in response to four natural antimicrobial compounds and sodium hypochlorite. Front. Microbiol. 11:617473. doi: 10.3389/fmicb.2020.617473

Molva, C., and Baysal, A. H. (2015). Evaluation of bioactivity of pomegranate fruit extract against Alicyclobacillus acidoterrestris DSM 3922 vegetative cells and spores in apple juice. LWT Food Sci. Technol. 62, 989-995. doi: 10.1016/j.lwt. 2015.02.021

Noorbakhsh, M.-F., Hayati, F., Samarghandian, S., Shaterzadeh-Yazdi, H., and Farkhondeh, T. (2018). An overview of hepatoprotective effects of thymoquinone. Recent Pat. Food Nutr. Agric. 9, 14-22. doi: 10.2174/ 2212798410666180221105503

Pei, J. J., Yue, T. L., Yuan, Y. H., and Dai, L. (2017). Activity of paracin C from lactic acid bacteria against Alicyclobacillus in apple juice: application of a novelty bacteriocin. J. Food Safety 37, e12350. doi: 10.1111/jfs.12350

Piskernik, S., Klančnik, A., Demšar, L., Smole Možina, S., and Jeršek, B. (2016). Control of Alicyclobacillus spp. vegetative cells and spores in apple juice with rosemary extracts. Food Control 60, 205-214. doi: 10.1016/j.foodcont.2015.07. 018

Pornpukdeewattana, S., Jindaprasert, A., and Massa, S. (2020). Alicyclobacillus spoilage and control - a review. Crit. Rev. Food Sci. 60, 108-122. doi: 10.1080/ 10408398.2018.1516190

Prado, D. B. d, Fernandes, M. d. S, dos Anjos, M. M., Tognim, M. C. B., Nakamura, C. V., Machinski, M. Jr., et al. (2018). Biofilm-forming ability of Alicyclobacillus spp. isolates from orange juice concentrate processing plant. J. Food Safety 38:e12466. doi: 10.1111/jfs.12466

Prado, D. B. d, Szczerepa, M. M. d. A, Capeloto, O. A., Astrath, N. G. C., Santos, N. C. A. d, Previdelli, I. T. S., et al. (2019). Effect of ultraviolet (UV-C) radiation on spores and biofilms of Alicyclobacillus spp. in industrialized orange juice. Int. J. Food Microbiol. 305:108238. doi: 10.1016/j.ijfoodmicro.2019.108238

Savaş Bahçeci, K., Gökmen, V., and Acar, J. (2004). Formation of guaiacol from vanillin by Alicyclobacillus acidoterrestris in apple juice: a model study. Eur. Food Res. Technol. 220, 196-199. doi: 10.1007/s00217-0041018-y

Shemesh, M., Pasvolsky, R., and Zakin, V. (2014). External pH is a cue for the behavioral switch that determines surface motility and biofilm formation of Alicyclobacillus acidoterrestris. J. Food Prot. 77, 1418-1423. doi: 10.4315/0362028x.Jfp-13-425

Shi, C., Yan, C., Sui, Y., Sun, Y., Guo, D., Chen, Y., et al. (2017). Thymoquinone inhibits virulence related traits of Cronobacter sakazakii ATCC 29544 and has anti-biofilm formation potential. Front. Microbiol. 8:2220. doi: 10.3389/fmicb. 2017.02220

Shi, C., Zhao, X., Yan, H., Meng, R., Zhang, Y., Li, W., et al. (2016). Effect of tea tree oil on Staphylococcus aureus growth and enterotoxin production. Food Control 62, 257-263. doi: 10.1016/j.foodcont.2015.10.049

Smit, Y., Cameron, M., Venter, P., and Witthuhn, R. C. (2011). Alicyclobacillus spoilage and isolation - a review. Food Microbiol. 28, 331-349. doi: 10.1016/j. fm.2010.11.008

Song, Z., Niu, C., Wu, H., Wei, J., Zhang, Y., and Yue, T. (2019). Transcriptomic analysis of the molecular mechanisms underlying the antibacterial activity of IONPs@pDA-Nisin composites toward Alicyclobacillus acidoterrestris. ACS Appl. Mater. Inter. 11, 21874-21886. doi: 10.1021/acsami.9b02990

Sun, Z. L., Zhang, X. X., Wu, H. H., Wang, H. Y., Bian, H., Zhu, Y. Z., et al. (2020). Antibacterial activity and action mode of chlorogenic acid against Salmonella Enteritidis, a foodborne pathogen in chilled fresh chicken. World J. Microb. Biot. 36:10. doi: 10.1007/s11274-020-2799-2

Sutton, K. M., Greenshields, A. L., and Hoskin, D. W. (2014). Thymoquinone, a bioactive component of black caraway seeds, causes G1 phase cell cycle arrest and apoptosis in triple-negative breast cancer cells with mutant p53. Nutr. Cancer 66, 408-418. doi: 10.1080/01635581.2013.878739

Xu, Y., Shi, C., Wu, Q., Zheng, Z., Liu, P., Li, G., et al. (2017). Antimicrobial activity of punicalagin against Staphylococcus aureus and its effect on biofilm formation. Foodborne Pathog. Dis. 14, 282-287. doi: 10.1089/fpd.2016.2226

Yang, J., Kuang, X., Lv, P., and Yan, X. (2015). Thymoquinone inhibits proliferation and invasion of human nonsmall-cell lung cancer cells via ERK pathway. Tumor Biol. 36, 259-269. doi: 10.1007/s13277-014-2628-z

Conflict of Interest: The authors declare that the research was conducted in the absence of any commercial or financial relationships that could be construed as a potential conflict of interest.

Copyright (c) 2021 Fan, Liu, Gao, Hu, Wang, Xiao, Yuan and Yue. This is an openaccess article distributed under the terms of the Creative Commons Attribution License (CC BY). The use, distribution or reproduction in other forums is permitted, provided the original author(s) and the copyright owner(s) are credited and that the original publication in this journal is cited, in accordance with accepted academic practice. No use, distribution or reproduction is permitted which does not comply with these terms. 